11 Kerr S, Jowett S. Sleep problems in pre-school children: a review of the literature. Child: Care, Health Dev 1994;20:379-91.

12 Stores G. Practitioner review: assessment and treatment of sleep disorders in children and adolescents. J Child Psychol Psychiatry 1996;37:907-25.

13 Anders TF, Eiben LA. Pediatric sleep disorders: a review of the past 10 years. J Am Acad Child Adolesc Psychiatry 1997;36:9-20.

14 Richman N. A double-blind drug trial of treatment in young children with waking problems. J Child Psychol Psychiatry 1985;26:591-8.

15 Rickert VI, Johnson CM. Reducing nocturnal awakening and crying episodes in infants and young children. A comparison between scheduled awakenings and systematic ignoring. Pediatrics 1988;81:203-12.

16 Douglas J, Richman N. My child won't sleep. London: Penguin, 1984.

17 Ferber R. Solve your child's sleep problem. New York: Simon and Schuster, 1985.

18 Simonoff EA, Stores G. Controlled trial of trimeprazine tartrate for night waking. Arch Dis Child 1987;62:253-7.
19 France KG, Blampied NM, Wilkinson P. Treatment of infant sleep disturbance by trimeprazine in combination with extinction. Dev Behav Pediat 1991;12:308-14.

20 Montanari G, Schiaulini P, Covre A, Steffan A, Furlanut M. Niaprazine vs chlormethyldiazepam in sleep disturbances in pediatric outpatients. Pharmacol Res 1992;25(suppl 1):83-4.

21 Jadad AR, Moore RA, Carroll D, Jenkinson C, Reynolds DJM, Gavaghan DJ, et al. Assessing the quality of reports of randomized clinical trials: is blinding necessary? Control Clin Trials 1996;17:1-12.

22 Pritchard AA, Appleton P. Management of sleep problems in pre-school children. Early Child Dev Care 1988;34:227-40.

23 Scott G, Richards MPM. Night waking in infants: effects of providing advice and support for parents. J Child Psychol Psychiatry 1990;31:551-67.

24 Paul FM. Sleep disturbance in young children. Singapore Fam Physician $1982 ; 8: 111-3$

(Accepted 5 November 1999)

\title{
Bacteraemia and antibiotic resistance of its pathogens reported in England and Wales between 1990 and 1998: trend analysis
}

\author{
Mark H Reacher, Anita Shah, David M Livermore, Martin C J Wale, Catriona Graham, \\ Alan P Johnson, Hilary Heine, Marjorie A Monnickendam, Keith F Barker, Dorothy James, \\ Robert C George
}

\begin{abstract}
Objectives Determination of causes, trends, and antibiotic resistance in reports of bacterial pathogens isolated from blood in England and Wales from 1990 to 1998 .

Design Description of bacterial isolates from blood, judged to be clinically significant by microbiology staff, reported to the Communicable Disease Surveillance Centre.

Setting Microbiology laboratories in England and Wales.

Subjects Patients yielding clinically significant isolates from blood.

Main outcome measures Frequency and Poisson regression analyses for trend of reported causes of bacteraemia and proportions of antibiotic resistant isolates.

Results There was an upward trend in total numbers of reports of bacteraemia. The five most cited organisms accounted for over $60 \%$ of reports each year. There was a substantial increase in the proportion of reports of Staphylococcus aureus resistant to methicillin, Streptococcus pneumoniae resistance to penicillin and erythromycin, and Enterococcus faecalis and Enterococcus faecium resistance to vancomycin. No increase was seen in resistance of Escherichia coli to gentamicin.

Conclusions Reports from laboratories provide valuable information on trends and antibiotic resistance in bacteraemia and show a worrying increase in resistance to important antibiotics.
\end{abstract}

\section{Introduction}

Culture of blood is a fundamental investigation in infection. Illness associated with bacteraemia ranges from self limiting infection to life threatening sepsis that requires rapid and aggressive antimicrobial treatment, ${ }^{1}$ which is complicated by increasing antibiotic resistance worldwide. ${ }^{2-5}$ Information on trends and antibiotic resistance in bacteraemia is needed to inform prescribing and infection control policy and to guide development of new antibiotics and vaccines. ${ }^{13-7}$

Since 1989 blood isolates judged to be clinically significant by microbiologists working in laboratories in England and Wales have been reported to the Public Health Laboratory Service Communicable Disease Surveillance Centre; this moved from paper to electronic transmission with EpiBase ${ }^{8}$ then CoSurv. Trends in resistance to key antibiotics have been published for Staphylococcus aureus, ${ }^{10}{ }^{11}$ Streptococcus pneumoniae, ${ }^{12}$ and Escherichia coli. ${ }^{13}$ Here we present the first overall description of the system and causative organisms with further information on antibiotic resistance.

\section{Methods}

Blood isolates reported to the surveillance centre from 1990 to 1998 were entered on a computer database (LabBase). ${ }^{8}$ Replicate reports were identified by matching on date of birth, sex, specimen date, organism, antibiotic susceptibility, and source laboratory and merged if the specimen dates were less than eight days apart. This was undertaken manually from 1990 to 1994 and then by computer program.

We identified laboratories in England and Wales that reported blood isolates to the surveillance centre in 1998 from the Directory of the Association of Medical Microbiologists. ${ }^{14}$ Annual total bacteraemias and annual counts for each of 34 "categories" of bacteraemia defined by causative organism ${ }^{15}$ were analysed by Poisson regression analysis. ${ }^{16}$ Categories showing a year on year proportional increase were further analysed within age groups. The causes of bacteraemia between age groups were examined.
Editorial by Amyes

Public Health

Laboratory Service

Communicable

Disease

Surveillance Centre London NW9 5EQ

Mark H Reacher

consultant

epidemiologist

Anita Shah

information officer

Hilary Heine

head of information

unit

Antibiotic

Resistance

Monitoring and

Reference

Laboratory, PHLS

Central Public

Health Laboratory,

London NW9 5HT

David M Livermore

director

Alan P Johnson

clinical scientist

Dorothy James

information officer

Respiratory and

Systemic Infection

Laboratory, PHLS

Central Public

Health Laboratory

Robert C George

director

PHLS

Antimicrobial

Susceptibility

Surveillance Unit,

Queen's Medical

Centre, Nottingham

NG7 2UH

Martin C J Wale

head

continued over

BMJ 2000;320:213-6 
PHLS Statistics

Unit, London

NW9 5EQ

Catriona Graham

statistician

PHLS

Headquarters,

London

NW9 5DF

Marjorie A

editor

International

Medical

Department

SmithKline

Beecham, SB

House, Brentford,

Middlesex

TW8 9BD

Keith F Barker

senior medical adviser

Correspondence to:

M Reacher

mreacher@

phls.nhs.uk
Monnickendam
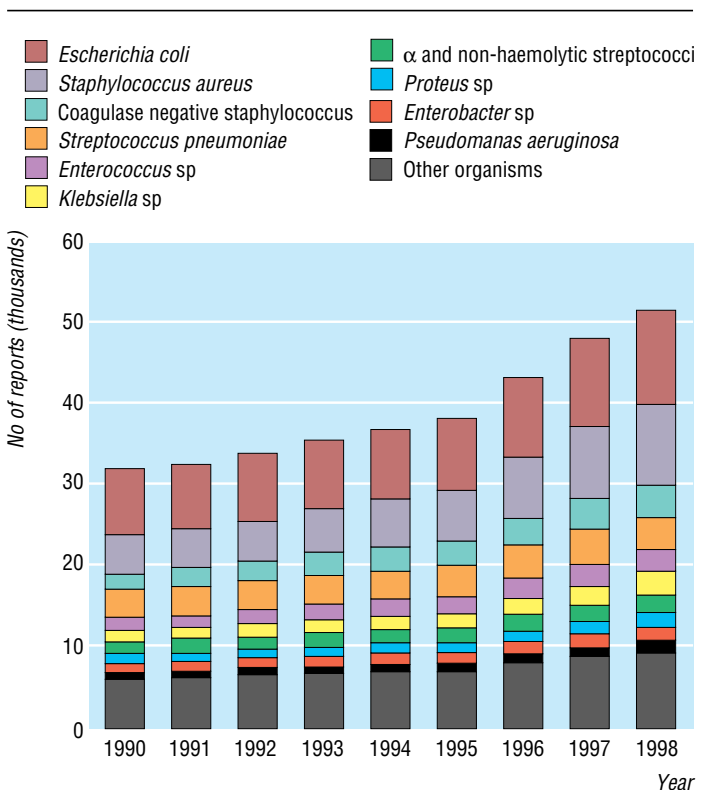

Fig 1 Incidence of commonly reported causes of bacteraemia in England and Wales, 1990 to 1998

Trends in the proportion resistant were determined for the subset of reports with a completed antibiotic susceptibility field. Intermediate resistance was recorded in less than $0.7 \%$ of reports and was counted as resistance.

\section{Results}

Of 229 laboratories identified in England and Wales in the directory, ${ }^{14} 208$ (91\%) reported blood isolates to the surveillance centre in 1998. Reports increased from 31763 in 1990 to 51232 in $1998(\mathrm{P}<0.05)$ (fig 1). E coli, Staph aureus, coagulase negative staphylococci, Strep pneumoniae, and either Enterococcus

Table 1 Causative organisms of bacteraemia, showing year on year proportional increasing trend by Poisson regression analysis, 1990-8

\begin{tabular}{lc} 
Category of bacteraemia & \% Annual increase $\mathbf{~} \mathbf{9 5} \mathbf{C} \mathbf{~ C I})$ \\
\hline Corynebacterium spp and diphtheroids & $16.9(14.7$ to 19.1$)$ \\
\hline Acinetobacter spp & $16.7(15.2$ to 18.1$)$ \\
\hline Serratia spp* & $14.7(13$ to 16.5$)$ \\
\hline Citrobacter spp & $9.2(7.6$ to 10.9$)$ \\
\hline Enterobacter spp & $9.0(8.2$ to 9.8$)$ \\
\hline Group C streptococci & $6.4(3.7$ to 9.2$)$ \\
\hline$\alpha$ and non-haemolytic streptococci (excluding pneumococci) ${ }^{*}$ & $6.2(5.5$ to 6.9$)$ \\
\hline${ }^{*}$ Approximately log linear. &
\end{tabular}

Table 2 Numbers of reports of bacteraemia and report rate per 100000 by age group in England and Wales, 1998. Denominators for rates were mid-year population estimates for England and Wales (Office for National Statistics, London)

\begin{tabular}{lcc} 
Age group (years) & No of reports (thousands) & No of reports per $\mathbf{1 0 0} \mathbf{0 0 0}$ \\
\hline$<1$ & 2.318 & 366.19 \\
\hline $1-4$ & 1.256 & 48.03 \\
\hline $5-9$ & 0.618 & 17.88 \\
\hline $10-14$ & 0.484 & 14.51 \\
\hline $15-44$ & 6.985 & 31.76 \\
\hline $45-64$ & 10.853 & 89.67 \\
\hline $65-74$ & 10.466 & 237.84 \\
\hline$\geqslant 75$ & 17.000 & 437.30
\end{tabular}

species (including E faecium, E faecalis, and group D streptococci) or Klebsiella species (fig 1) accounted for $60 \%$ of all reports each year. A further $20 \%$ comprised either Klebsiella species or Enterococcus species, $\alpha$ and non-haemolytic streptococci (other than pneumococci), and Proteus species, Enterobacter species, and Pseudomonas aeruginosa.

Poisson regression showed a year on year proportional increase for seven categories (table 1) that was also present within each age group. Haemophilus influenzae declined steeply from 1992. Most reports were from adults but the reporting rate was high in infants: 1149 reports for infants aged 0-28 days and 1169 for infants aged 29 to 365 days in 1998 (table 2).

Staph aureus was among the top five causes of bacteraemia in every age group, whereas $E$ coli, coagulase negative staphylococci, Strep pneumoniae, and Enterococcus species ranked lower at certain ages (fig 2). $\alpha$ and non-haemolytic streptococci (excluding pneumococci) accounted for $5-7 \%$ of bacteraemias in children of all ages and for $2-4 \%$ aged over 14 years. Group B streptococci comprised $22 \%$ of reports in infants aged 0 to 28 days, $5 \%$ in infants aged 29 days to 1 year, were rare in children aged between 1 and 14 years (three reports in 1998), but contributed $1-2 \%$ in the adult age groups. Neisseria meningitidis accounted for $11-17 \%$ of reports in age groups from birth to 14 years, $2 \%$ from 15 to 44 years, and less than $1 \%$ in older age groups. The proportion of reports contributed by each age group to each category of bacteraemia was similar in every year.

The subset of reports with completion of the antibiotic susceptibility field generally declined in 1996 and 1997 and recovered in 1998 (fig 3). Methicillin resistance in Staph aureus increased from 1.7\% to 3.8\% from 1990 to 1993 , rose steeply to $32 \%$ in 1997 and to 34\% in 1998 (fig 3). Gentamicin resistance in E coli
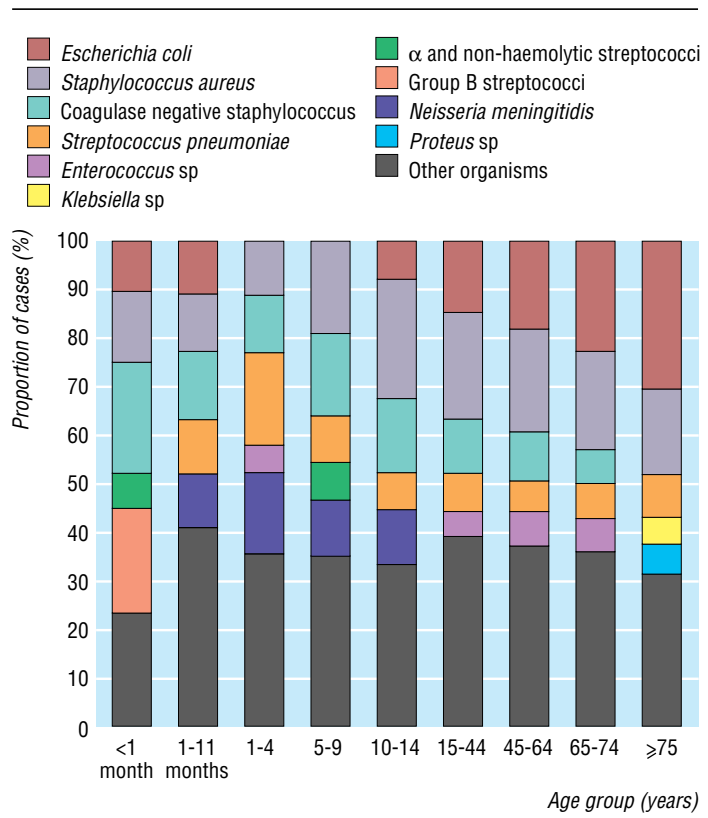

Fig 2 Common causes of bacteraemia by age group as proportion of total reports for England and Wales, 1998 (age group <1 month equals $\leqslant 28$ days; $1-11$ months equals $29-365$ days) 

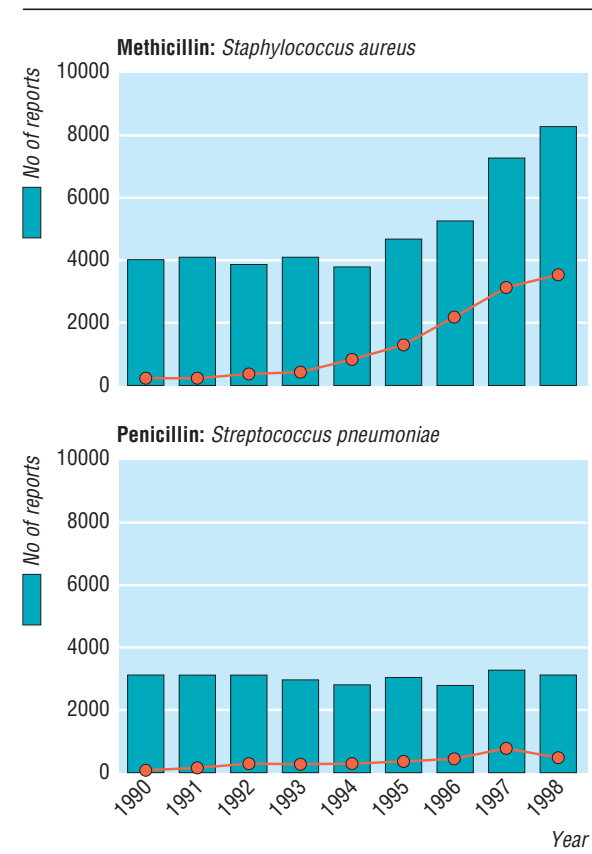

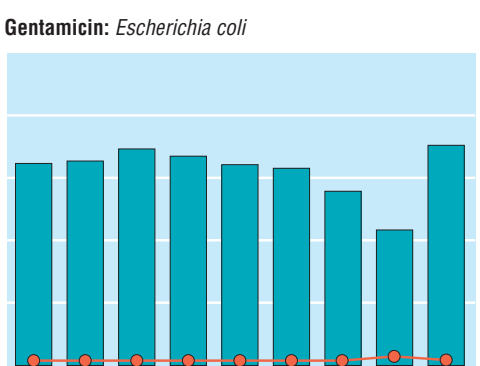

Erythromycin: Streptococcus pneumoniae

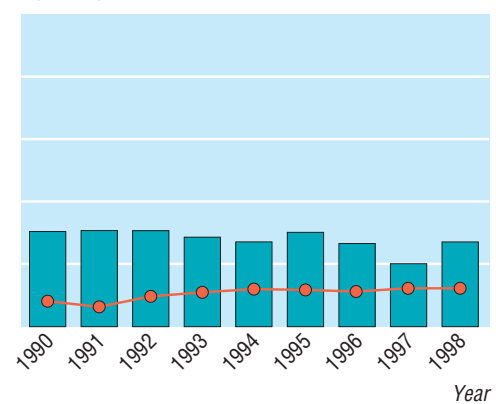

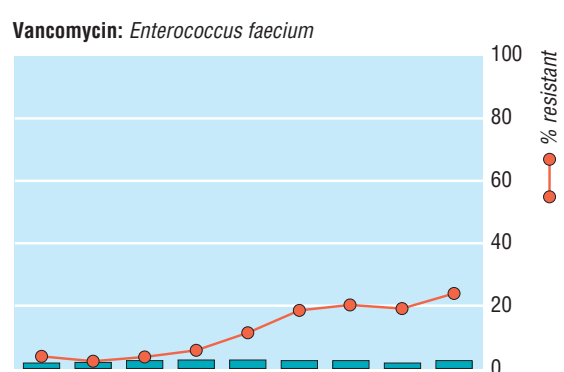

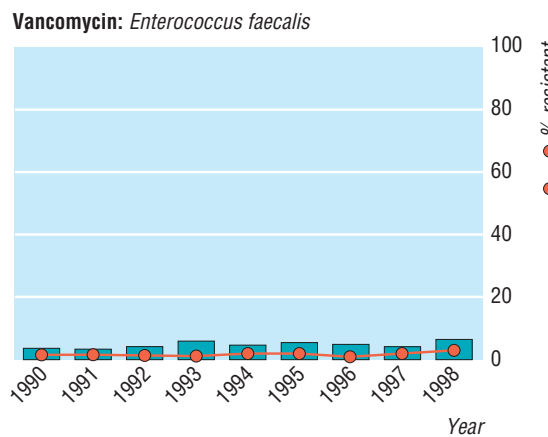

Fig 3 Antibiotic resistance ((number resistant + number intermediate)/(number resistant + number intermediate + number sensitive) $x 100)$ in bacteraemia isolates (lines) and numbers of reports with antibiotic susceptibility data (bars) in England and Wales, 1990 to 1998

increased from $1.7 \%$ in 1990 to 3\% in 1997 declining to $2.2 \%$ in 1998. Vancomycin resistance in Ent faecium reached $6.3 \%$ in $1993,20 \%$ in 1995, and 24\% in 1998. Vancomycin resistance in Ent faecalis was under $3 \%$ from 1990 to 1996 , increasing to $5 \%$ in 1998. Ampicillin resistance, however, was recorded in 15\% of Ent faecalis and ampicillin sensitivity in $17 \%$ of Ent faecium reports in 1998, suggesting frequent mis-speciation. Penicillin resistance in Strep pneumoniae was under 1\% in 1990 and 1991 , increasing to $3.7 \%$ in 1996 , to $7.4 \%$ in 1997 , and $3.6 \%$ in 1998. Erythromycin resistance in Strep pmeumoniae increased from 5\% in 1990 to stabilise at about 11\% from 1994 onwards.

\section{Discussion}

The number of reports increased yearly; a steep increase between 1996 and 1998 (fig 1) coincided with efforts to encourage reporting, including "free" installation of CoSurv into laboratories, but the number bearing data on antimicrobial susceptibility did not increase except for methicillin against Staph aureus (fig 3). This was probably due to problems in the introduction of CoSurv and different degrees of effort in chasing up missing results for each antimicrobial susceptibility. Increased reporting may also have reflected rising incidence due to improved survival of severely ill patients. ${ }^{17} 18$

The causes of bacteraemia were similar to those seen in other large series. ${ }^{17-19}$ Categories with a marked upward trend (table 1) are a priority for further research. The trend for Corynebacterium species and diphtheroids may reflect a change from regarding these organisms as skin contaminants to being clinically significant, as occurred for coagulase negative staphylococci. ${ }^{20}$ Marked increases in Acinetobacter species, Serratia species, Citrobacter species, and Enterobacter species may reflect their facility to develop muta- tional resistance to cephalosporin antibiotics, which were used increasingly during the survey period. We found no shift to Gram positive organisms as reported elsewhere. ${ }^{17-20}$ This may have occurred before the study period or be specific to certain patient groups, such as patients with neutropaenia. The fall in $\mathrm{H}$ influenzae followed introduction of Hib immunisation in 1992. ${ }^{21}$

The rise in antibiotic resistance in blood isolates emphasises the importance of sound hospital infection

\section{What is already known on this subject}

Bacteraemia series from laboratories and programmes of nosocomial infection surveillance are generally derived from individual or small numbers of institutions

The collated data may be unrepresentative of the general population and inferences may lack precision because of the small number of reports

The need for representative and precise information on the causes and trends in antibiotic resistance in blood stream infections at national level made an overview of the system desirable at this time

\section{What this paper adds}

Over $90 \%$ of laboratories in England and Wales reported clinically significant blood isolates to the communicable disease surveillance centre in 1998, with total reports ranging from about 30000 in 1990 to 50000 in 1998

This reporting system probably captures information on a sizeable proportion of episodes of bacteraemia at national level

The value of this system for national level monitoring of antibiotic resistance and trends in the causes of bacteraemia has been demonstrated; regional analyses with multivariable methods may prove useful in the future 
control, ${ }^{67}$ rational prescribing policies, and the need for new antimicrobial drugs and vaccines. ${ }^{3-5}$ Validation of reported data on resistance has been undertaken by comparison with centralised testing of nationally representative sample strains. ${ }^{13}$ Regional analyses have been developed for methicillin against Staph aureus ${ }^{22}$ (http://www.phls.co.uk/facts/bact.htm). Further analysis of these data could include the determination of the independent effect on antibiotic resistance of region, year, age, and sex by using multivariable methods. ${ }^{16}$ This national reporting system should complement local surveillance of bacteraemia in which extensive data on risk factors may be collected. ${ }^{23} 24$

We thank the microbiology laboratory staff in England and Wales for reporting isolates to the surveillance centre.

Contributors: MHR designed and coordinated the study, supervised the downloading and analysis of data, and wrote the paper. AS retrieved and processed data. DML advised on the design of the study and reviewed and contributed to writing the paper. MCJW advised on the design of the study and reviewed the paper. CG undertook the statistical analyses. APJ contributed to the design of the project and reviewed the paper. $\mathrm{HH}$ advised and assisted in the retrieval of data and reviewed the paper. MAM and KFB developed the routine bacteraemia reporting system, which provided the framework for this paper, and each reviewed the paper. DJ monitored the completeness of antibiotic susceptibility reporting and chased up missing data. RCG advised on design of the project and reviewed the paper. MHR, DML, and HH are guarantors for the paper.

Funding: Public Health Laboratory Service.

Competing interests: None declared.

1 Young LS. Sepsis syndrome. In: Mandell GL, Bennett JE, Dolin R, eds. Principles and practice of infectious diseases. New York: Churchill Principles and practice of

2 Livermore D, MacGowan AP, Wale MCJ. Surveillance of antimicrobial resistance. BMJ 1998;317:614-5.

3 House of Lords Select Committee on Science and Technology. Resistance to antibiotics and other antimicrobial agents. London: Stationery Office, 1998.

4 Standing Medical Advisory Committee: Subgroup on Antimicrobial Resistance. The path of least resistance. London: Department of Health, 1998.

5 Wise R, Hart T, Cars O, Streulens M, Helmuth R, Huovinen P, et al. Antimicrobial resistance is a major threat to public health. BMJ 1998;317:609-10.
6 Duckworth G, Cookson B, Humphreys H, Heathcock R. Working party report: revised guidelines for the control of methicillin-resistant Staphylococcus aureus infection in hospitals. J Hosp Infect 1998;39:253-90.

7 Hospital Infection Working Group of the Department of Health and the Public Health Laboratory Service. Hospital infection control:guidance on the control of infection in hospitals. London: Department of Health, 1995.

8 Grant AD, Eke E. Application of information technology to the laboratory reporting of communicable disease in England and Wales. Commun Dis Rep CDR Rev 1993;3:R75-8.

9 Henry R. CoSurv: a regional computing strategy for communicable disease surveillance. PHLS Microbiol Digest 1996;13:26-8.

10 Speller DCE, Johnson AP, James D, Marples RR, Charlett A, George RC. Resistance to methicillin and other antibiotics in isolates of Staphylococcus aureus from blood and cerebrospinal fluid, England and Wales, 198995. Lancet 1997;350:323-5.

11 Johnson AP, James D, Livermore DM. Increasing prevalence of methicillin-resistance amongst Staphylococcus aureus blood culture isolates. J Antimicrob Chemother 1999;43:160.

12 Laurichesse H, Grimaud O, Waight P, Johnson AP, George RC, Miller E. Pneumococcal bacteraemia and meningitis in England and Wales, 1993 to 1995 . Commun Dis Publ Hlth 1998;1:22-7.

13 Livermore DM, Threlfall EJ, Reacher MH, Johnson AP, James D, Cheasty $\mathrm{T}$, et al. Are routine sensitivity test data suitable for the surveillance of resistance? Resistance rates amongst Escherichia coli from blood and CSF from 1991-97 as assessed by routine and centralised testing. J Antimicrob Chemother (in press).

14 Anonymous. $A M M$ directory: medical microbiology services in the United Kingdom and the Republic of Ireland. St Leonards on Sea: Association of Medical Microbiologists, 1998;139-43.

15 Anonymous. Look inside: the presentation of bacteraemia data in the CDR weekly has changed. Commun Dis Report CDR Wkly 1997;7:13.

16 Clayton D, Hills M. Poisson and logistic regression. In: Statistical models in epidemiology. Oxford: Oxford University Press, 1993;227-36.

17 Bannerjee SN, Emori TG, Culver DH, Gaynes RP, Jarvis WR, Horan T, et al. Secular trends in nosocomial bloodstream infections in the United States. Am J Med 1991;91(suppl 3B):86-9S.

18 Pittet D, Wenzel RP. Nosocomial bloodstream infections. Arch Int Med 1995; $155: 1177-84$

19 Cockerill FR, Hughes JG, Vetter EA, Mueller RA, Weaver A L, Ilstrup DM, et al. Analysis of 281,797 consecutive blood cultures performed over an eight-year period: trends in micro-organisms isolated and the value of anaerobic culture of blood. Clin Infect Dis 1997;24:403-18.

20 Johnson AP. Antibiotic resistance among clinically important Gram positive bacteria in the UK. J Hosp Infect 1998;40:17-26.

21 Hargreaves RM, Slack MPE, Howard AJ, Anderson E, Ramsay ME. Changing patterns of invasive Haemophilus influenzae disease in England and Wales after introduction of the Hib vaccination programme BMJ 1996;312:160-1

22 Anonymous. Staphylococcus aureus bacteraemia: England and Wales, January to March 1999. Commun Dis Rep CDR Wkly 1999;9:185.

23 Anonymous. Nosocomial infection national surveillance scheme. Commun Dis Report CDR Wkly 1996;6:83.

24 Anonymous. National nosocomial infections surveillance (NNIS) system report, data summary from October 1986-April 1998, issued June 1998 Am J Infect Control 1998;26:522-33.

(Accepted 5 November 1999)

\section{A memorable patient Disability is in the mind of the beholder}

I met Dave in 1992, when we were both inpatients at a spinal injuries unit. Dave, a man in his early 30 s, had suffered a complete high cervical spinal cord injury after diving into a swimming pool on holiday. His upper limb movement was extremely limited, which meant that he would need the use of an electrically powered wheelchair for mobility and help from others for most other things. I had sustained a complete midthoracic spinal cord injury in a tobogganing accident, resulting in permanent paraplegia.

We had both been in hospital for a couple of months and we were at the stage of being put in wheelchairs. We were sitting in the ward and passing the time of day. I was finding the unsteady and vulnerable experience of wheelchair use quite frightening and unfamiliar. I asked Dave how he was getting on. Dave, who was very articulate, said something that really struck me, especially since my thoughts had been sensitised as to how important independence was. He said that he had been okay with all that had happened to him since his accident, until the other day. It was then that he had been put in a wheelchair for the first time. This chair was not motorised, and so a nurse pushed him to where he wanted to go. He had been left alone for a few minutes and it was at that moment that he felt completely stranded and utterly hopeless. He could not move anywhere unless he screamed for help. This made me look at myself and think how independent I was, rather than how dependent I was. I could not walk or do many of the things that I previously did, but I had not felt such extremes of isolation and total dependence. At the same time, I thought that there were people with more severe impairments than Dave. Dave was still cerebrally intact and able to attempt to rationalise his situation.

Time has passed. Dave now has the equipment that he needs and a full time carer. He is working again in a worthwhile job. I would never judge the extent of Dave's disablement: only he can quantify that. His few words did, however, drive home that living with a long term impairment is dynamic and idiosyncratic.

Tom Wells medical senior house officer, Bristol

We welcome articles of up to 600 words on topics such as A memorable patient, A paper that changed my practice, My most unfortunate mistake, or any other piece conveying instruction, pathos, or humour. If possible the article should be supplied on a disk. Permission is needed from the patient or a relative if an identifiable patient is referred to. We also welcome contributions for "Endpieces," consisting of quotations of up to 80 words (but most are considerably shorter) from any source, ancient or modern, which have appealed to the reader. 